\title{
Clinical and Genetics Findings in Möbius Syndrome: Role of Hoxa1 and Hoxb1 Mutations
}

\section{Lineu Perrone Jr', Felipe Perozzo Daltoé ${ }^{1,2}$, Luiz Carlos Areas Araújo3 , Fabio Daumas Nunes ${ }^{1}$, Marina Helena Cury Gallottini ${ }^{1}$ and Andrea Mantesso ${ }^{1}$}

${ }^{1}$ Department of Oral Pathology, School of Dentistry, University of Sao Paulo, Sao Paulo, Brazil

${ }^{2}$ Department of Pathology, Federal University of Santa Catarina, Florianopolis, Brazil

${ }^{3}$ Fleury Institute, Sao Paulo, Brazil

*Corresponding author: Felipe Perozzo Daltoé, MSD, PhD, Department of Oral Pathology, School of Dentistry, University of Sao Paulo; Department of Pathology, Health Sciences Center, Federal University of Santa Catarina, Street Defino Conte, University Campus, Trindade, 88040-900, Florianópolis, SC, Brazil, Tel: +55-48-3207-5068

\section{Abstract}

Möbius syndrome (MBS) is a rare congenital neurological disorder typically characterized by the absence or underdevelopment of the 6 th and $7^{\text {th }}$ cranial nerves, causing a loss of facial expression and strabismus. Other cranial nerves may be affected in addition to other structures such as the jaw, limbs, and anterior chest. While the primary cause of MBS has not yet been identified different hypotheses have been enumerated, including a possible genetic alteration. The Hoxb1 gene may be a good candidate as mutations of the gene in animals yield a phenotype closely resembles features of the clinical profile associated with humans suffering from MBS. Another good candidate gene may be Hoxa1 giving its implications in the development of the hindbrain, cranial nerves and ear in a possible functional synergy with Hoxb1. In this study we analyzed mutations in Hoxb1 and in its paralogue Hoxa1 in 29 MBS patients and also analyzed the feasible correlation between familial history and MBS by comparing the presence of polymorphisms in the compromised individuals with those found in their relatives and in unrelated people. Furthermore, we investigated whether the incidence of polymorphisms is associated with the severity of the patient's phenotype and whether the presence of polymorphisms is correlated with pregnancy intercurrences or the use of misoprostol during gestation. Finally, we investigated the effects of pregnancy intercurrences and use of misoprostol in patients' phenotype. Our results do not establish a clear link between a specific mutation and the others parameter analyzed concluding that the complex pattern of development of MBS stems from a heterogeneous etiology, which involves both genetic and environmental aspects.
\end{abstract}

\section{Keywords}

Möbius syndrome, Hoxa1, Hoxb1, Misoprostol

\section{Introduction}

Möbius syndrome (MBS) is a congenital unilateral or bilateral palsy of the abducens (VI) and facial (VII) cranial nerves. This disorder can be associated with palsy of other cranial nerves such as the trigeminal (V), glossopharyngeal (IX) and/or hypoglossal nerve (XII). Other malformations such as craniofacial and orofacial anomalies (e.g., cleft palate, abnormalities of the tongue, micrognathia), and limb malformations (e.g., ectrodactyly, syndactyly, arthrogryposis) can occur concurrently with MBS [1].

The precise etiology and pathogenesis of the syndrome are uncertain. The most accepted pathogenic mechanism is a circulatory disorder at early stages of development. In most cases, no genetic etiology has been identified but familial occurrence has been described [2]. Mutations in Hoxa1 and Hoxb1 genes have been proposed to play a role in the development of MBS [3-5] but in Brazil, an environmental cause such as the use of abortifacients like misoprostol also has been described $[6,7]$.

Brazilian law bans abortion except in special condi-

Citation: Perrone L, Daltoé FP, Araújo LCA, Nunes FD, Gallottini MHC, et al. (2019) Clinical and Genetics Findings in Möbius Syndrome: Role of Hoxa1 and Hoxb1 Mutations. Int J Pathol Clin Res 5:085. doi. org/10.23937/2469-5807/1510085

Accepted: January 12, 2019: Published: January 14, 2019

Copyright: (c) 2019 Perrone L, et al. This is an open-access article distributed under the terms of the Creative Commons Attribution License, which permits unrestricted use, distribution, and reproduction in any medium, provided the original author and source are credited. 
tions as in the case of pregnancy after rape. The existence of a black market for selling abortifacients medications such as misoprostol is one of the consequences of this prohibition. Unfortunately, purchase of misoprostol in such circumstances compounded with the lack of quality control is often associated with improper use, which may contribute to the high numbers of Möbius patients found in Brazil. The Dental School of the University of São Paulo is the largest in Brazil and because it is a countrywide referral center for special care dentistry, the number of Möbius patients is significantly high.

We investigated a possible correlation between mutations in Hoxa1 and Hoxb1 genes and MBS. In addition, we analyzed the feasible correlation between familial history and MBS comparing the presence of polymorphisms in the compromised patient's group with those found in their relatives and in biologically unrelated individuals. Furthermore, we investigated whether the incidence of polymorphisms was associated with the severity of the patient's phenotype and whether the presence of polymorphisms was correlated with pregnancy intercurrences or with the use of misoprostol during gestation. And finally, we investigated whether pregnancy intercurrences or the use of misoprostol could independently influence the patients' phenotype.

\section{Methods}

\section{Setting and patients}

For 3 years, we examined a total of 59 patients with Möbius syndrome from the Special Care Dentistry Center at School of Dentistry, University of São Paulo, Brazil. Thirty patients were included in the present study. For ethical reasons, only individuals under dental treatment could be included, as patients should not be mobilized for the sake of the study.

Thirty individuals with MBS (group 1), of which fourteen were women (47\%) and sixteen were men $(53 \%)$, were assessed by two trained and calibrated dentists using CLUFT grading system as previously described in Abramson, et al. 1998 [8]. This system categorizes and grades the cranial nerve deficits and diverse musculoskeletal abnormalities of the face, upper and lower limbs and trunk. The first letter for each of five potentially involved structures - cranial nerve, lower limb, upper limb, face, and thorax - formed the acronym CLUFT. The structural and/or functional deficits for each component were graded on a scale of 0 to 3 (Table 1). For the control's groups, we enrolled 15 MBS individuals' relatives (Group 2) and 15 nonsyndromic and non-consanguineous individuals (Group 3).

In addition, from the patients' files and/or from direct inquiry of the patient's caretakers, we obtained information related to prenatal medical history such as any kind of intercurrence during gestation and the use of medications, notably misoprostol. When documenting medicine use, trimester of pregnancy was noted. Furthermore, the presence of other syndrome or malformation in a member of the family was investigated for details about the phenotype and familial relation with the affected individual. To obtain this information, the caretakers were asked to state if any other member of the family presented characteristics similar to the MBS individuals or any other type of physical malformation.

\section{DNA extraction}

Five cytobrushes (Gentra Puregene Cell Kit ${ }^{\circledR}$ Quiagen ${ }^{\odot}$ ) were used per study participant and rotated 10 times on the oral mucosa. The collected cells were put in $1.5 \mathrm{ml}$ eppendorf tubes with sterile lysis solution and DNA extraction followed the manufacturer's protocol. After extraction, samples were stored at -70 ${ }^{\circ} \mathrm{C}$ for later use.

\section{Amplification and sequencing}

The gene of interest was polymerase chain reaction (PCR)-amplified with the following oligonucleotide primers: Hoxa1, (sense) 5' GCAAGAATGAACTCCTTCCTG, (antisense) 3'-ACCAACCAGCAGGACTGACCT; and Hoxb1, (sense) 5' GCATGGACTATAATAGGATG, (antisense) 3' TCTTGGGTGGGTTTCTCTTA).

Amplification for Hoxa1 consisted of initial denaturation at 94 for $3 \mathrm{~min}$ and following 40 cycles of $94{ }^{\circ} \mathrm{C}$ (for $40 \mathrm{sec}$ ); $64{ }^{\circ} \mathrm{C}$ (for $45 \mathrm{sec}$ ); $72{ }^{\circ} \mathrm{C}$ (for $1 \mathrm{~min}$ ); $72{ }^{\circ} \mathrm{C}$ (for $5 \mathrm{~min}$ ), producing a 661-bp fragment. Amplification

Table 1: CLUFT grading system.

\begin{tabular}{|c|c|}
\hline Cranial nerve & Grade \\
\hline $\mathrm{VII}^{\text {th }}$ nerve partial & 0 \\
\hline $\mathrm{VI}^{\text {th }}$ and $\mathrm{VII}$ th partial & 1 \\
\hline $\mathrm{VI}^{\text {th }}$ and $\mathrm{VI}{ }^{\text {th }}$ complete & 2 \\
\hline Additional nerve involvement & 3 \\
\hline If bilateral and equal add & B \\
\hline \multicolumn{2}{|l|}{ Lower limb } \\
\hline Normal & 0 \\
\hline Talipes equinovarus, syndactyly, ankylosis & 1 \\
\hline Absent phalanges & 2 \\
\hline Longitudinal or transverse deficits & 3 \\
\hline \multicolumn{2}{|l|}{ Upper limb } \\
\hline Normal & 0 \\
\hline Digital hypoplasia or failure of differentiation & 1 \\
\hline Ectrodactyly & 2 \\
\hline Failure of formation, longitudinal or transverse & 3 \\
\hline \multicolumn{2}{|l|}{ Facial structure } \\
\hline Normal & 0 \\
\hline Cleft palate & 1 \\
\hline Micrognathia & 2 \\
\hline Microtia, microphthalmia, abnormal joint, etc. & 3 \\
\hline \multicolumn{2}{|l|}{ Thorax } \\
\hline Normal & 0 \\
\hline Scoliosis & 1 \\
\hline Pectoral hypoplasia or breast anomaly & 2 \\
\hline Chest wall deformity, breast or pectoral aplasia & 3 \\
\hline
\end{tabular}


for Hoxb1 consisted of the same cycling, but with the annealing temperature of $58{ }^{\circ} \mathrm{C}$, resulting in a 576-bp fragment. Part of the amplicons were electrophoresed on a $2 \%$ agarose gel and stained with ethidium bromide. The other part was stored at $-20^{\circ} \mathrm{C}$ for sequencing.

Amplicons were sequenced with the MegaBACE $1000^{\circledR}$ equipment (Amersham Biosciences) utilizing AP Biotech DYnamic ET Dye Terminator Cycle Sequencing Kit (with Thermo Sequenase ${ }^{\mathrm{TM}}$ || DNA Polimerase) according to manufacturer's instructions. The analysis was carried out using the Lasergene ${ }^{\circledR}$ software (DNAstar INC). The amplicons of the test and control groups were compared with the published sequences of Hoxa1 and Hoxb1 in the GenBank (www.ncbi.nlm.nih.gov/ genbank/).

\section{Analysis}

Data analyses were assessed in probands, their relatives (15 patients) and in non-syndromic and nonconsanguineous patients (15 patients). The analyses included search for mutations as single nucleotides polymorphisms (SNP) or insertions/translocations of bp catalogued at PubMed date baseline as well as possible new alterations.

All genetic findings were evaluated by Fisher's exact test with the software STATA 8.2. (Intercooled Stata 8.2 for Windows, StataCorp LP, 2005; College Station TX - USA). The genetic data was correlated with the phenotype of Möbius patients (graduated by CLUFT system), with prenatal medical history (intercurrence during pregnancy, use of misoprostol and/or other medication) and presence of other syndromes or malformations in the family. Furthermore, after this initial correlation analysis, all the data collected in the prenatal history and presence of other syndromes and malformations in the family were compared independently with each other.

\section{Results}

All patient's findings obtained in this study are depicted in Table 2. Facial nerve involvement was present in all individuals from group 1 , being bilateral

Table 2: Clinical findings.

\begin{tabular}{|c|c|c|c|c|c|c|c|c|}
\hline \multicolumn{3}{|c|}{ Pregnancy History/Month } & \multicolumn{5}{|c|}{ CLUFT } & \multirow{2}{*}{$\begin{array}{l}\text { Relatives with MBS or } \\
\text { other abnormalities } \\
\text { Degree of Kinship: } \\
\text { Abnormality }\end{array}$} \\
\hline 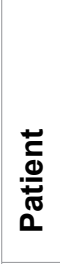 & Medical problem (month) & Medicine used (month) & $\begin{array}{l}\frac{0}{0} \\
\frac{0}{2} \\
\frac{\pi}{\frac{\pi}{\pi}} \\
\frac{\pi}{0}\end{array}$ & 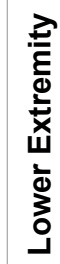 & 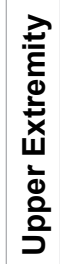 & 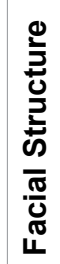 & $\underset{\mathfrak{L}}{\stackrel{2}{2}}$ & \\
\hline 1 & - & Misoprostol $\left(3^{\text {rd }}\right)$ & 1B & 0 & 0 & 2 & 0 & - \\
\hline 2 & Bleeding & Antiallergenic + anti haemorrhagic $\left(2^{\mathrm{ed}}\right)$ & 1B & 3 & 3 & 2 & 2 & $\begin{array}{l}\text { First-degree cousin: S. } \\
\text { Cornelia de Lange }\end{array}$ \\
\hline 3 & Bleeding + pneumonia & Antibiotic $\left(3^{\text {rd }}\right)$ & 2 & 3 & 0 & 1 & 0 & - \\
\hline 4 & Pyoderma $\left(2^{\mathrm{ed}}\right)$ & Misoprostol + penicillin $\left(2^{\text {ed }}\right)$ & 3B & 3 & 0 & 2 & 0 & $\begin{array}{l}\text { First-degree uncle: Down`s } \\
\text { S./First-degree cousin: } \\
\text { congenital blindness }\end{array}$ \\
\hline 5 & Widespread erythema $\left(2^{\text {ed }}\right)$ & - & 3 & 3 & 3 & 2 & 1 & - \\
\hline 6 & Car accident (clavicle fracture) & Analgesic & 0 & 0 & 0 & 2 & 0 & $\begin{array}{l}\text { First-degree cousin: } \\
\text { Down`s S. }\end{array}$ \\
\hline 7 & - & - & 3B & 3 & 3 & 2 & 0 & $\begin{array}{l}\text { First-degree cousin: } \\
\text { Down`s S. }\end{array}$ \\
\hline 8 & Rubella & - & 3 & 1 & 0 & 0 & 0 & $\begin{array}{l}\text { First-degree uncle: Down`s } \\
\text { S./Third-degree uncle: } \\
\text { Down`s S./Third degree } \\
\text { cousin: Neurofibromatosis }\end{array}$ \\
\hline 9 & - & Misoprostol $\left(1^{\text {st }}\right)$ & 3B & 3 & 0 & 2 & 3 & $\begin{array}{l}\text { First-degree uncle: Lack } \\
\text { of de uvula, upper lip hypo } \\
\text { mobility, face weakness } \\
\text { and strabismus }\end{array}$ \\
\hline 10 & Gastritis & Ranitidine $\left(2^{\text {ed }}\right)$ & 2B & 0 & 3 & 2 & 3 & - \\
\hline 11 & $\begin{array}{l}\text { There was no movement of the } \\
\text { foetus }\end{array}$ & Misoprostol (1 $\left.1^{\text {st }}\right)$ & 0 & 3 & 0 & 2 & 1 & $\begin{array}{l}\text { Brother: Talipes } \\
\text { equinovarus }\end{array}$ \\
\hline 12 & Hypertension & $\begin{array}{l}\text { Misoprostol + contraceptive + } \\
\text { antihypertensive }\left(1^{\text {st }}\right)\end{array}$ & 3 & 0 & 1 & 2 & 1 & $\begin{array}{l}\text { Second-degree cousin: } \\
\text { Motor disability/Other } \\
\text { relatives presented visual } \\
\text { impairment not specified }\end{array}$ \\
\hline 13 & - & Misoprostol $\left(1^{\text {st }}\right.$ and $\left.2^{\text {ed }}\right)$ & $3 B$ & 3 & 0 & 3 & 3 & - \\
\hline
\end{tabular}




\begin{tabular}{|c|c|c|c|c|c|c|c|c|}
\hline 14 & $\begin{array}{l}\text { Uterine bleeding after fall } \\
\text { (ending of pregnancy) }\end{array}$ & $\begin{array}{l}\text { Misoprostol + antibiotic + diclofenac } \\
\text { sodium + laxative }\left(1^{\text {st }}\right)\end{array}$ & 1B & 1 & 0 & 2 & 0 & $\begin{array}{l}\text { Second-degree uncle: } \\
\text { Ondine Syndrome/Third- } \\
\text { degree cousin: shortened } \\
\text { leg }\end{array}$ \\
\hline 15 & Fall & Misoprostol (month not specified) & 3B & 0 & 1 & 2 & 0 & $\begin{array}{l}\text { First-degree cousin: } \\
\text { Paralysis of lower limbs }\end{array}$ \\
\hline 16 & Stress & - & 3B & 1 & 0 & 2 & 0 & $\begin{array}{l}\text { First-degree cousin: } \\
\text { Syndactyly/First-degree } \\
\text { cousin: hypoxia at birth } \\
\text { and motor disorders/First- } \\
\text { degree cousin: Fragile X } \\
\text { syndrome }\end{array}$ \\
\hline 17 & Stress & - & 0 & 1 & 0 & 2 & 1 & - \\
\hline 18 & $\begin{array}{l}\text { Urinary infection }+ \text { treat of } \\
\left.\text { abortion/( } 1^{\text {st }}\right)\end{array}$ & $\begin{array}{l}\text { Antibiotic }+ \text { antiallergenic }+ \\
\text { contraceptive }\left(4^{\text {th }}\right)\end{array}$ & 3 & 0 & 0 & 2 & 0 & $\begin{array}{l}\text { Second-degree uncle: } \\
\text { Physical deformity and } \\
\text { speech impairment/Third- } \\
\text { degree cousin: unknown } \\
\text { syndrome } \\
\text { Deformidade física } \\
\text { e problemas de fala/ } \\
\text { Síndrome não esclarecida }\end{array}$ \\
\hline 19 & - & Misoprostol $/ 2^{\circ}$ & 1 & 0 & 0 & 2 & 0 & - \\
\hline 20 & Stress & Misoprostol (2ed $)$ & 0 & 0 & 0 & 2 & 0 & $\begin{array}{l}\text { First-degree cousin: Thorax } \\
\text { and heart malformation/ } \\
\text { Second-degree cousin: } \\
\text { Hypoplastic thorax and } \\
\text { abnormal lower limbs }\end{array}$ \\
\hline 21 & - & - & $3 B$ & 0 & 0 & 2 & 1 & - \\
\hline 22 & Fall + early childbirth $\left(5^{\text {th }}\right)$ & - & 1 & 0 & 3 & 2 & 0 & $\begin{array}{l}\text { First-degree uncle: Cleft } \\
\text { palate/Second--degree } \\
\text { cousin: Down`s S. }\end{array}$ \\
\hline 23 & - & Analgesic + antiallergenic $\left(2^{\mathrm{ed}}\right)$ & 3B & 3 & 0 & 2 & 3 & - \\
\hline $24^{\mathrm{a}}$ & - & - & - & - & - & - & - & - \\
\hline 25 & $\begin{array}{l}\text { Mumps }\left(2^{\text {ed }}\right)+\text { uterine bleeding } \\
\left(3^{\text {rd }}\right)\end{array}$ & - & 2B & 3 & 2 & 2 & 0 & - \\
\hline 26 & Vaginal bleeding $\left(1^{\text {st }}-9^{\text {th }}\right)$ & Misoprostol $\left(1^{\text {st }}\right)$ & 3B & 3 & 1 & 2 & 1 & - \\
\hline 27 & Uterine bleeding $\left(7^{\text {th }}\right)$ & Dipyrone $\left(2^{\text {ed }}\right)$ & $3 B$ & 0 & 0 & 2 & 0 & - \\
\hline 28 & Hypertension & $\begin{array}{l}\text { Aldomet }+ \text { bethametasone }+ \text { diclofenac } \\
\text { sodium }\left(1^{\text {st }} \text { to } 9^{\text {th }}\right)\end{array}$ & 2B & 3 & 0 & 2 & 0 & $\begin{array}{l}\text { First-degree cousin: } \\
\text { Short limbs and e } \\
\text { gastroesophageal reflux/ } \\
\text { Second--degree cousin: } \\
\text { MBS and visual deficiency }\end{array}$ \\
\hline 29 & Stress & Misoprostol (1 $\left.1^{\text {st }}\right)$ & 0 & 0 & 0 & 2 & 0 & $\begin{array}{l}\text { First--degree uncle: Visual } \\
\text { deficiency }\end{array}$ \\
\hline 30 & $\begin{array}{l}\text { Urinary infection + uterine } \\
\text { bleeding }\end{array}$ & Antibiotic + antiallergenic $\left(2^{\text {ed }}\right)$ & $2 B$ & 3 & 0 & 2 & 0 & - \\
\hline
\end{tabular}

aPatient didn't return for clinical evaluation.

in $90 \%$ of the cases $(27 / 30)$. The upper face was more affected than the lower, but 26 patients (86.6\%) also presented hypomobility of the lower face. The hypoglossal nerve was affected in 15 patients (50\%). Other facial structures such as the eyes, palate and mandible were compromised in $10 \%$ of the individuals with MBS (3/30) (Figure $1 \mathrm{~A})$.

Facial abnormalities as epicanthic folds, flattened nasal bridge, cleft palate and dental malformations were concurrently found but some patients were more affected than others (Figure 1A and Figure 1B).

The thorax, lower and upper limbs showed involvement in $36.7,53.3$ and $30 \%$ of the MBS cases, respectively (Table 2). Some Möbius patients had short limbs, loss of digits, ectrodactyly, talipes equinovarus, brachydactyly, syndactyly, camptodactilia and/or arthroses (Figure 2).

Three patients (number 6, 20 e 29 in Table 2) with the lowest CLUFT (00020) presented normal facial mobility on the lower and medium third of the face and one of them had a satisfactory ocular unilateral mobility. These patients did not present with any anomalies on the upper or lower limbs and on the thorax. The MBS patients frequently had micrognathia.

The most serious case of MBS (patient 13 in Table 2 - CLUFT 3B3033) presented with severe facial weakness, strabism, micrognathia, total loss of mobility of the tongue, microphthalmia, micrognathia, talipes equinovarus, short lower and upper limbs, hypoplastic pectoralis, lack of balance and hydrocephaly. 

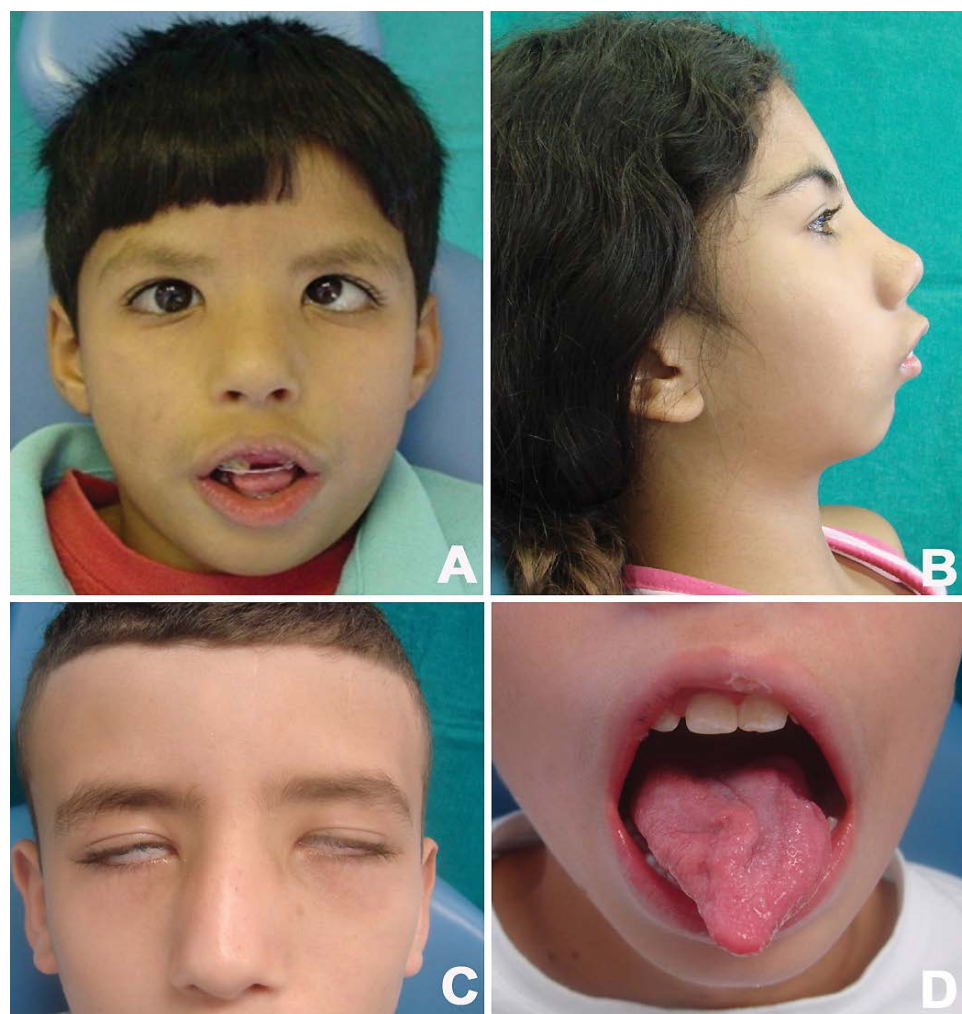

Figure 1: Facial aspects often seen in MBS' individuals. A) Mask-like face, large angle esotropia; B) Facial convex profile, micrognathia and short philtrum height; C) Incomplete eyelid closure; D) Tongue abnormalities.

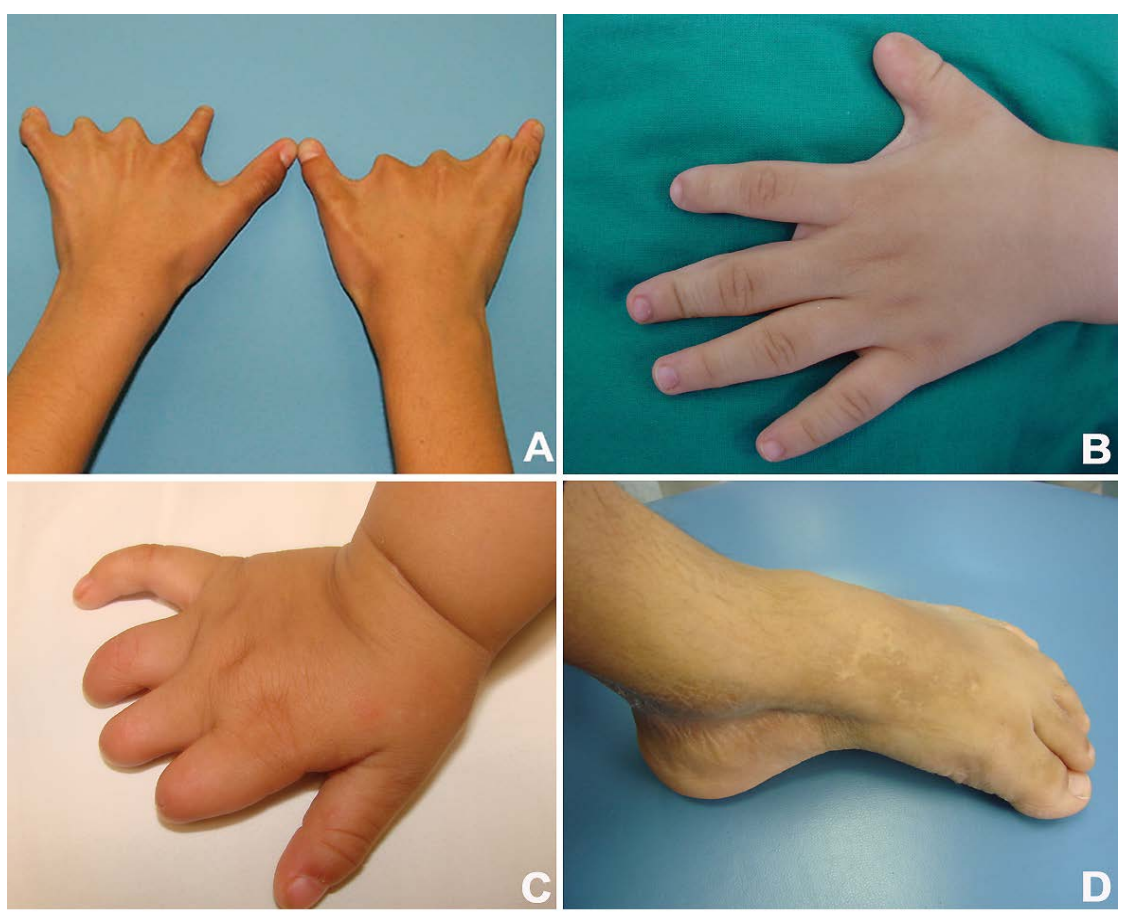

Figure 2: Clinical features commonly seen MBS patients' limbs. Clinical features commonly seen MBS patients' limbs. A and C) Ectrodactyly; B) Syndactly; D) Corrected clubfoot deformity.

Twelve Möbius individuals (40\%) were exposed to misoprostol during the first trimester of pregnancy. Two of the less affected patients were exposed to misoprostol during the first and second months of pregnancy, respectively, but the patient with the most severe MBS phenotype (patient 13 above mentioned) also admitted exposure to misoprostol during the first and second months of pregnancy.
When comparing use of misoprostol with involvement of cranial nerves classified by CLUFT system it was possible to find a significant difference between use of misoprostol and involvement of the "upper limb (U)" ( $p$ $=0.02$ ) $.100 \%$ of the mothers of patients with $U=1$ used misoprostol during pregnancy but $80 \%$ of the mothers of patients with $U=3$ (more severe upper limb phenotype) did not use the misoprostol during pregnancy or 
omitted this information from the examiners.

Eight patient mothers' mentioned use of other medication other than misoprostol during pregnancy. The medication used (depicted in Table 2) was variable in terms of type or month of gestation used, and thus, we could not find any specific pattern.

Eighteen patients (54\%) stated at least one form of intercurrences during pregnancy (bleeding accidents, diseases), and four of them were in abortion risk according to health caretaker. The patients who could not specify the type of gestational intercurrence or who only related stress as intercurrence were not considered in this analysis. There were no statistically significant differences between intercurrences during pregnancy and exposure to medications other than misoprostol with the incidence of MBS or severity of the clinical phenotype.

Among 15 individuals from group 1 (affected individuals), five (cases 9, 11, 12, 18 and 28 in Table 2) presented relatives with phenotype common to MBS: brother with talipes equinovarus (patient 11), uncle with facial weakness and strabismus (patient 9), second-degree cousin with motor palsy (patient 12) and a second-degree cousin with MBS (patient 28). Down syndrome was the most common syndrome found in MBS patient's relatives and occurred in 6 families. None of these families could be submitted to a supplementary genetic analysis given their geographic removal from the location of the study. No individuals from groups 2 and 3 showed any disturbance on face, limbs or chest.

All the DNA samples (from groups 1, 2 and 3) were sequenced. The genetic materials were compared with the DNA sequences available at GeneBank and they showed more than 95\% homology. Nucleotides alterations were found in both Hoxa1 and Hoxb1 genes in all groups analyzed (Möbius patients, their relatives (group 2) and in non-syndromic and nonconsanguineous patients (group 3).

For the Hoxa1 gene, only one single nucleotide polymorphism was observed (G218A) (Figure 3A', Figure $3 A^{\prime \prime}$ and Figure $\left.3 A^{\prime \prime}\right)$. For Hoxb1, there was an insertion of $9 \mathrm{bp}$ and 3 single nucleotide polymorphisms (C243T; A315T; G456A) on the first exon (Figure 3B and Figure $\left.3 B^{\prime}\right)$. Although these changes are polymorphisms, only the polymorphism G218A (Hoxa1), A315T (Hoxb1) and the insertion of $9 \mathrm{bp}$ on Hoxb1 gene results in change of protein transcription.

When comparing polymorphisms in MBS patients, their parents and the control group, there is a significant difference only in the polymorphisms C243T, A315T and G456A. The polymorphism C243T ( $p=$ 0.03 ) is homozygous (CC) in $73.3 \%$ of MBS patients and heterozygous (CT) in $46.7 \%$. Two samples of the control group still had presented with the nucleosides TT. The polymorphism A315T $(p=0.01)$ presented the nucleosides AA in $86.7 \%$ of MBS patients while in $46.7 \%$

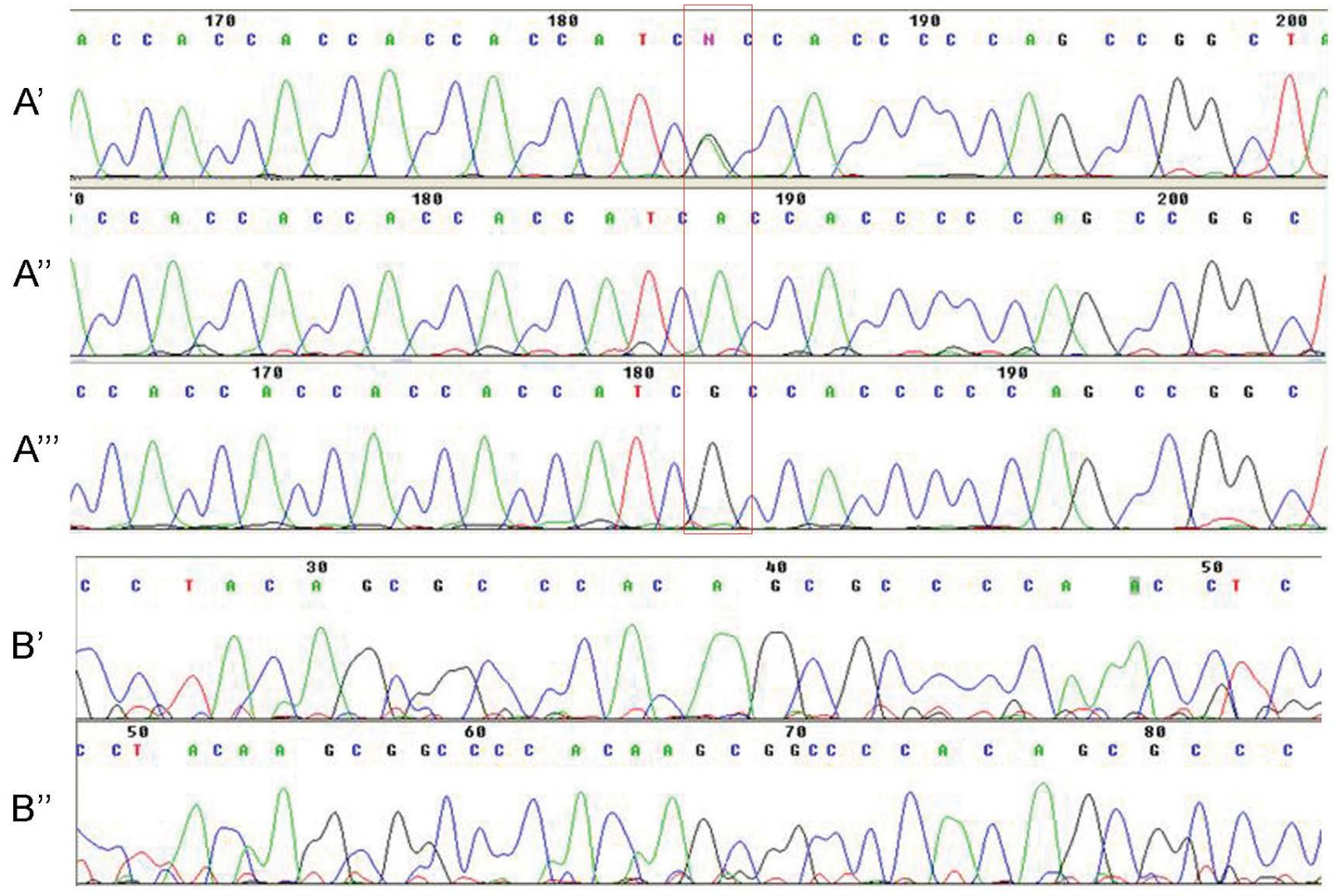

Figure 3: Electropherograms of Hoxa1 (A', A" and A"') and Hoxb1 genes (B' and B"). A') Hoxa1 G218A polymorphism; A") Wild-type gene sequence; A"') Homozygous polymorphism; B') Wild-type sequence and B") Insertion of 9pb. 
Table 3: Statistical significant dates involving Hox polymorphisms.

\begin{tabular}{|c|c|c|c|c|c|}
\hline Groups & Polymorphism & Nucleoside & MBS patients $(n=30)$ & Control groups $(n=30)$ & p-value \\
\hline \multirow{4}{*}{$\begin{array}{l}\text { MBS patients Versus } \\
\text { Non-MBS patients }\end{array}$} & \multirow{4}{*}{ A315T (Hoxb1) } & & MBS patients $(n=30)$ & Non-MBS patients $(n=30)$ & \\
\hline & & AA & $26(86.7)$ & $17(56.7)$ & 0.02 \\
\hline & & AT & $4(13.3)$ & $12(40)$ & \\
\hline & & TT & $0(0)$ & $1(3.3)$ & \\
\hline \multirow{10}{*}{$\begin{array}{l}\text { MBS patients Versus } \\
\text { Non-consanguineous } \\
\text { and Non-syndromic } \\
\text { patients (control } \\
\text { group 2) }\end{array}$} & \multirow{4}{*}{ C243T (Hoxb1) } & & MBS patients $(n=30)$ & $\begin{array}{l}\text { Non-consanguineous and non- } \\
\text { syndromic }(n=15)\end{array}$ & p-value \\
\hline & & $\mathrm{CC}$ & $22(73.3)$ & $6(40)$ & 0.03 \\
\hline & & CT & $8(26.7)$ & $7(46.7)$ & \\
\hline & & TT & $0(0)$ & $2(13.3)$ & \\
\hline & \multirow{3}{*}{ A315T (Hoxb1) } & AA & $26(86.7)$ & $7(46.6)$ & 0.01 \\
\hline & & AT & $4(13.3)$ & $7(46.7)$ & \\
\hline & & TT & $0(0)$ & $1(6.7)$ & \\
\hline & \multirow{3}{*}{ G456A (Hoxb1) } & GG & $20(66.7)$ & $5(33.3)$ & 0.02 \\
\hline & & GA & $10(33.3)$ & $7(46.7)$ & \\
\hline & & AA & $0(0)$ & $3(20)$ & \\
\hline \multirow{4}{*}{$\begin{array}{l}\text { MBS patients Versus } \\
\text { Their relatives } \\
\text { (Control group 1) }\end{array}$} & \multirow{4}{*}{ G218A (Hoxa1) } & & MBS patients $(n=30)$ & Consanguineous $(n=15)$ & $p$-value \\
\hline & & GG & $0(0)$ & $1(6.6)$ & 0.03 \\
\hline & & GA & $11(36.7)$ & $1(6.7)$ & \\
\hline & & AA & $19(63.3)$ & $13(86.7)$ & \\
\hline
\end{tabular}

of the patients of the control group had the nucleosides AA and other $46.7 \%$ of them had the nucleosides AT. Only one person presented with nucleosides TT. With regard to the G456A polymorphism, $66.7 \%$ of the patients were homozygous for GG while only 3 individuals of the control group were homozygous and $46.7 \%$ were heterozygous (GA) (Table 3 ).

When comparing polymorphisms among MBS patients and their relatives (control group 1), only the G218A polymorphism showed statistical significance $(p$ $=0.03$ ). $63.3 \%$ of the patients and $86.7 \%$ of their relatives had the AA nucleosides in their genomes. However, when comparing the presence of polymorphisms in the relatives of MBS patients (GROUP 2) and the GROUP 3 , no polymorphism was found to be of any significance.

It was possible to establish a positive correlation between clinical impairment of "Lower Limb (L)" classified by CLUFT system and the polymorphisms C243T $(p<0.01)$, G456A ( $p=0.02)$ and insertion of $9 p b$ $(p<0.01)$. Interestingly, for the C243T polymorphism, $100 \%$ of the patients with $\mathrm{L}=3$ had the nucleosides CC in their genome while only $60 \%$ of the patients with $\mathrm{L}$ $=1$ presented this same homozygous pattern. At the same time none of them presented the nucleosides TT. To the G456A polymorphism, $92.3 \%$ of the patients with $\mathrm{L}=3$ had nucleosides $\mathrm{GG}$ and only $58.3 \%$ of the patients with $L=1$ had this same homozygosis. $58.3 \%$ of the patients with $L=0$ had nucleosides $G$. Any of them had nucleosides $\mathrm{AA}$. In relation with the insertion of $9 \mathrm{pb}$, $100 \%$ with $L=3$ and $60 \%$ with $L=1$ had no insertion of $\mathrm{pb}$.

When performing analysis for A218G the polymorphisms C243T comparing MBS patients to controls (group 2 and 3), a significant difference was observed $(p=0.03)$ between presence of the nucleosides CC in the MBS $(73.3 \%$ of the cases) and the group 3 ( $40 \%$ of the non-syndromic and non-consanguineous patients). Likewise, the presence of the nucleoside GG in the polymorphism G456A was found in $66.7 \%$ of MBS patients in contrast with $33.3 \%$ in the control group $2(p=0.02)$. Furthermore, $60 \%$ of the controls $(46.6 \%$ of the control group 2 and $73.3 \%$ of the control group 1) had no insertion of $\mathrm{pb}$.

Significant positive correlation could also be observed among patients with involvement of XII cranial nerves and the polymorphisms A315T $(p=0.04)$ and G456A ( $p$ $=0.02$ ). $100 \%$ of the patients with the polymorphism A315T had nucleosides AA in contrast with just $56.7 \%$ of the controls (46.6\% of the control group 2 and $66.7 \%$ of control group 1). Similarly, $86.7 \%$ of those with the polymorphism G456T had nucleosides GG while just $46.7 \%$ of the controls presented the same $(60 \%$ of the non-syndromic relatives and $33.3 \%$ of the non-relatives and non-syndromic).

Moreover, none of the genetic alterations had significant correlation with gestational intercurrences or use of misoprostol.

\section{Discussion}

Möbius syndrome is a rare congenital disorder involving complete or partial facial nerve palsy with or without paralysis of their cranial nerves [2,9].

The etiology and the pathogenesis of the syndrome are currently unclear. Some authors believe that there are at least two different groups of patients with MBS. One group has been proposed to consist of patients with hereditary congenital facial palsy in which agenesis or hypoplasia of the cranial nerve nuclei is pathologically present and its penetrance is due to genetic or nongenetic factors. A second group of authors believe that the etiology of MBS is correlated with congenital hypoplasia of cranial nerve nuclei resulted from ischemia 
of the brainstem accompanied by necrosis, gliosis and calcifications owing to an environmental, mechanical or a genetic cause $[6,7,10,11]$. The mechanism has not been elucidated, but the cranial nuclei of the VI and VII nerves, which are located in the ventral part of the rhombencephalon, in a thin and dilated portion of the brain and with relative lack of tissue, appear to make them a particularly vulnerable structure. If flexion or trauma occurs in this area during early gestation like those by uterine contractions stimulated by abortifacients [7], decreased blood flow could follow as well hemorrhage and/or cell death in the cranial nuclei [12].

Considering a possible genetic etiology of MBS, different studies have shown possible candidates. While some authors speculate that a single chromosome deletion (chromosome 13q12.2) [13] or a single mutation in Hoxb1 gene (Arg207Cys) [14] could be involved in MBS etiopathogenesis others have found common genetic alterations (locus on chromosome 3q21-22) in MBS patients from a same family [15] and have excluded the possibility of involvement of other genes such as TPUg-BASP1 [16]. Additionally, animal models have shown that mutations of Hoxa1 affect the hindbrain, cranial nerves, ear [17-19], cardiovascular and cognitive development [19] and Hoxb1 gene disruption leads to defects in formation of the somatic motor component of the VII nerve (facial) similar of patients with MBS [5].

Our approach in searching for Hoxa1 and Hoxb1 alterations was based on previous studies in mice that suggested that these genes synergize in patterning the hindbrain, cranial nerves and derivatives of the pharyngeal arches, with the phenotype resembling features of the clinical profile associated with Möbius Syndrome in humans $[4,5,20]$.

In our study, it was possible to establish a positive correlation about the presence of the polymorphism G218A in the Hoxa1 when comparing MBS patients and their relatives. Conversely, another study reported that neither participant with Möbius syndrome and autism spectrum disorder harbored the G218A polymorphism [21].

Furthermore, although there are significant correlations between the presence of 3 single nucleotide polymorphisms (C243T; A315T; G456A) in Hoxb1 gene and MBS phenotypes, it was impossible to predict if these genetic alterations affected gene function and their relative contributions, if any.

As a whole, no type of polymorphism found in our study was specific and could be seen only in patients with Möbius patients. Even when patients presented a significant difference in the expression of a specific type of polymorphism, it could still be found in patient's relatives and/or non-syndromic and non-consanguineous individuals. Therefore, the results found in our genetic screening for Hoxa1and Hoxb1, cannot be considered entirely causative of the syndrome. However, we cannot exclude the possibility that the presence of some of the polymorphisms is contributory, for example by making some individuals more susceptible to environmental toxins or medications.

When investigating other factors in MBS etiopathogenesis as the possible correlation of use of abortifacients during pregnancy and MBS, we found that despite the exposure of twelve probands (40\%) to the misoprostol during the first trimester of gestation, drug use could not by itself be considered as the only etiogenic factor. However, we assume that the incorrect use of abortifacients as misoprostol are associated with an increased risk of Möbius' syndrome as previously described [7].

The termination of early pregnancy (up to 49 days of gestation) using combining misoprostol and mifepristone is a legal procedure in countries such as the UK $[22,23]$ and has been demonstrating to be effective and safe when performed with medical assistance [24]. In Brazil, abortion is illegal (except for cases of rape or incest or when the mother's life is at risk), but misoprostol is used to induce abortions given its low cost and accessibility in the black market [25]. Thus, in places like Brazil, the incorrect use of misoprostol results in up to 80 percent of the times the continuation of the pregnancy, increasing incidence of malformations in infants $[7,26]$.

Fifteen patients $(50 \%)$ reported to have relatives with some syndrome or malformation and four of them (13.3\%) have relatives with clinical characteristics similar to those of the Möbius patients. Interestingly Verzijl, et al. [27] analyzed the familial history of MBS in $37 \mathrm{MBS}$ patients and found just one case (a mother and her son with similar phenotype). Nevertheless, in the early 1990s a review presented 26 reports of "familial Mobius syndrome" [27].

All patients presented facial nerve involvement. According to prior literature, the upper face is more affected than the lower and the VIth and VIIth facial nerves are the most seriously involved followed by the hypoglossal (XII) and trigeminal (V) cranial-nerves $[6,12,28]$. Our results are consistent with those findings except for alterations on the trigeminal cranial nerve, which we could not observe, likely due to the absence of complementary exams as electromyography and electrostimulation.

The assessment of tongue involvement in Möbius patients by the CLUFT system showed to be difficult, as many patients had extrinsic but no intrinsic muscle function in the tongue. They could protrude, retract, depress and elevate the tongue but they could not lengthen or shorten it, curl or uncurl its apex and edges, or flatten and round its surface. Moreover, 
the innervation of the tongue is complex and involves several cranial nerves. All the muscles of the tongue are innervated by the hypoglossal nerve (cranial nerve XII) with one exception: the palatoglossal muscle, which is innervated by the $X$ cranial nerve (the Vagus nerve) via the pharyngeal plexus [29]. In our study, dimorphism of the tongue and range of motion limits was interpreted as hypoglossal nerve involvement, found in 15 patients (50\%).

In general, the CLUFT grade system was found to be inefficient to evaluate the phenotype of Möbius patients because: (I) many different alterations of the body structures are graded via the same score; (II) the scores did not reproduce patients phenotype precisely as highest CLUFTs scores do not determine the worst phenotypes or a worse condition of life; and (III) the CLUFT system does not evaluate the neurologic component. Another shortcoming of this clinical classification is its inability to account for the superposition of functions of the cranial nerves on the CLUFT grading system. As an example, the mandible trigeminal branch has both sensory and motor functions. The motor branches of the trigeminal nerve controls movement of eight muscles, including four muscles of mastication. With the exception of tensor tympani, all of these muscles are involved in biting, chewing and swallowing. The facial muscles are innervated by facial nerve (cranial nerve VII). In contrast, the nearby masticatory muscles are innervated by the mandible nerve, a branch of the trigeminal nerve (V) [29].

More recently, our group also suggested the use of the Oral Motor Assessment Scale (OMAS) to assess the motor functionality of the mouth in Möbius patients more precisely [30]. By changing the criteria and analysing mandibular and labial closing, lingual sealing, controlled solid and liquid swallowing, straw suction and chewing capacity, our group was able to establish a more reliable method for analysing the motor assessment of the oral region of individuals with Moebius syndrome.

Epicanthic folds flattened nasal bridge, micrognathia, high arch palate, external ear defects, teeth defects and hypertelorism are the most frequent craniofacial malformations features present in the Möbius patients [10]. In our patients a combination of all these features was frequently noted.

The thorax, lower and upper limbs showed a complex pattern of involvement. Some Möbius patients had short limbs, loss of digits, ectrodactyly, talipes equinovarus, brachydactyly, syndactyly, camptodactilia and/or arthroses while others developed these structures normally.

\section{Conclusions}

Familial history of MBS, intercurrences during pregnancy and prenatal use of misoprostol do not appear to act as isolated etiologic factors for MBS nor do they appear to severity of the clinical phenotype. Genetic alterations found in Hoxa1 and Hoxb1 suggest that the lack of association between pathogenic mutations and MBS exclude these genes as candidate genes in MBS etiopathogenesis. Any genetic alteration could be correlated with the use of misoprostol or intercurrences during early pregnancy. In fact, probably both environmental and/or genetic factors contribute to MBS etiology and severity and additional studies are necessary to elucidate these indices.

\section{Author's Contribution}

LPJ collected the clinical data and performed the genetic analysis. FPD, carried out data analysis and wrote the manuscript. LCAA and FDN are responsible for the genetic experiments design and their analysis. MHCG contributed with patient recruitment and critical reading of the manuscript. $A M$ is responsible for the study design and wrote the manuscript.

\section{Acknowledgments}

The authors thank the patients and their families for their participation in this study and Dr. Sofia Mizuho Miura Sugayama for the helpful insights about the methodology of the study.

\section{Compliance with Ethical Standards}

Conflict of Interest: The author Lineu Perrone Junior declares that he has no conflict of interest; the author Felipe Perozzo Daltoé declares that he has no conflict of interest; the author Luiz Carlos Areas Araújo declares that he has no conflict of interest; the author Fabio DaumasNunes declares that he has no conflict of interest; the author Marina Helena CuryGallottini declares that she has no conflict of interest; the author Andrea Mantesso declares that she has no conflict of interest.

\section{Funding}

The work was supported by the FAPESP (Sao Paulo Research Foundation) for Grant 04/02474-0.

\section{Ethical approval}

All procedures performed in studies involving human participants were in accordance with the ethical standards of the national research committee (project number 10355) and with the 1964 Helsinki declaration and its later amendments or comparable ethical standards.

\section{Informed consent}

Informed consent was obtained from all individual participants included in the study.

\section{References}

1. Kumar D (1990) Moebius syndrome. J Med Genet 27: 122126. 
2. Moebius PJ (1888) Über angeborene doppelseitige Abducens-Facialis-Lähmung. Munch Med Wochenschr 35: 91-94.

3. Carpenter EM, Goddard JM, Chisaka O, Manley NR, Capecchi MR (1993) Loss of Hox-A1 (Hox-1.6) function results in the reorganization of the murine hindbrain. Development 118: 1063-1075.

4. Gavalas A, Studer M, Lumsden A, Rijli FM, Krumlauf R, et al. (1998) Hoxa1 and Hoxb1 synergize in patterning the hindbrain, cranial nerves and second pharyngeal arch. Development 125: 1123-1136.

5. Goddard JM, Rossel M, Manley NR, Capecchi MR (1996) Mice with targeted disruption of Hoxb1 fail to form the motor nucleus of the VIIth nerve. Development 122: 3217-3228.

6. Gonzalez $\mathrm{CH}$, Marques-Dias MJ, Kim CA, Sugayama SM, Da Paz JA, et al. (1998) Congenital abnormalities in Brazilian children associated with misoprostol misuse in first trimester of pregnancy. Lancet 351: 1624-1627.

7. Pastuszak AL, Schüler L, Speck-Martins CE, Coelho KE, Cordello SM, et al. (1998) Use of misoprostol during pregnancy and Mobius' syndrome in infants. N Eng J Med 338: $1881-1885$.

8. Abramson DL, Cohen MMJ, Mulliken JB (1998) Möbius syndrome: Classification and grading system. Plast Reconstr Surg 102: 961-967.

9. Legum C, Godel V, Nemet P (1981) Heterogeneity and pleiotropism in the Moebius syndrome. Clin Genet 20: 254259.

10. Verzijl HTFM, Padberg GW, Zwarts MJ (2005) The spectrum of Mobius syndrome: An electrophysiological study. Brain 128: 1728-1736.

11. Lipson AH, Webster WS, Brown-Woodman PD, Osborn RA (1989) Möbius syndrome: Animal model--human correlations and evidence for a brainstem vascular etiology. Teratology 40: 339-350.

12. Shepard TH (1995) Möbius syndrome after misoprostol: A possible teratogenic mechanism. Lancet 346: 780.

13. Slee JJ, Smart RD, Viljoen DL (1991) Deletion of chromosome 13 in Moebius syndrome. J Med Genet 28: 413-414.

14. Webb BD, Shaaban S, Gaspar H, Cunha LF, Schubert $\mathrm{CR}$, et al. (2012) HOXB1 founder mutation in humans recapitulates the phenotype of Hoxb1-/- mice. Am J Hum Genet 13: 171-179.

15. Verzijl HT, Van Den Helm B, Veldman B, Hamel BC, Kuyt LP, et al. (1999) A second gene for autosomal dominant Möbius syndrome is localized to chromosome $10 \mathrm{q}$, in a Dutch family. Am J Hum Genet 65: 752-756.

16. Uzumcu A, Candan S, Toksoy G, Uyguner ZO, Karaman B, et al. (2009) Mutational screening of BASP1 and transcribed processed pseudogene TP $\Psi \mathrm{g}$-BASP1 in patients with Möbius syndrome. J Genet Genomics 36: 251-256.

17. Lufkin $T$, Dierich $A$, LeMeur $M$, Mark $M$, Chambon $P$ (1991) Disruption of the Hox-1.6 homeobox gene results in defects in a region corresponding to its rostral domain of expression. Cell 66: 1105-1110.

18. Chisaka O, Musci TS, Capecchi MR (1992) Developmental defects of the ear, cranial nerves and hindbrain resulting from targeted disruption of the mouse homeobox gene Hox-1.6. Nature 355: 516-520.

19. Tischfield MA, Bosley TM, Salih MA, Alorainy IA, Sener EC, et al. (2005) Homozygous HOXA1 mutations disrupt human brainstem, inner ear, cardiovascular and cognitive development. Nat Genet 37: 1035-1037.

20. Studer M, Gavalas A, Marshall H, Ariza-McNaughton L, Rijli FM, et al. (1998) Genetic interactions between Hoxa1 and Hoxb1 reveal new roles in regulation of early hindbrain patterning. Development 125: 1025-1036.

21. Rankin JK, Andrews C, Chan WM, Engle EC (2010) HOXA1 mutations are not a common cause of Mobius Syndrome. J AAPOS 14: 78-80.

22. Sitruk-Ware R, Davey A, Sakiz E (1998) Fetal malformation and failed medical termination of pregnancy. Lancet 352: 323.

23. (1997) The efficacy and tolerance of mifepristone and prostaglandin in termination of pregnancy of less than 63 days gestation; UK multicentre study--final results. Contraception 55: 1-5.

24. Peyron R, Aubény E, Targosz V, Silvestre L, Renault M, et al. (1993) Early termination of pregnancy with mifepristone (RU486) and the orally active prostaglandin misoprostol. New Engl J Med 328: 1509-1513.

25. Coêlho HL, Teixeira AC, Santos AP, Forte EB, Morais SM, et al. (1993) Misoprostol and illegal abortion in Fortaleza, Brazil. Lancet 341: 1261-1263.

26. Bos-Thompson MA, Hillaire-Buys D, Roux C, Faillie JL, Amram D (2008) Möbius syndrome in a neonate after mifepristone and misoprostol elective abortion failure. Ann Pharmacother 42: 888-892.

27. MacDermot KD, Winter RM, Taylor D, Baraitser M (1990) Oculofacialbulbar palsy in mother and son: Review of 26 reports of familial transmission within the Mobius spectrum of defects. J Med Genet 27: 18-26.

28. De Serpa Pinto MV, De Magalhães MH, Nunes FD (2002) Moebius syndrome with oral involvement. Int $\mathrm{J}$ Paediat Dent 12: 446-449.

29. Madeira MC (2001) Anatomia da Face. (3 $3^{\text {rd }}$ edn), Sarvier, Sao Paulo, 179-195.

30. Ortega A de O, Marques-Dias MJ, Santos MT, Castro T, Gallottini M (2014) Oral motor assessment in individuals with Moebius syndrome. J Oral Pathol Med 43: 157-161. 